Daniel Kajanek - Branislav Hadzima - Matej Brezina - Martina Jackova*

\title{
EFFECT OF APPLIED CURRENT DENSITY OF PLASMA ELECTROLYTIC OXIDATION PROCESS ON CORROSION RESISTANCE OF AZ31 MAGNESIUM ALLOY
}

Impact of applied current density during the plasma electrolytic oxidation (PEO) process on corrosion resistance of AZ31 magnesium alloy was studied. The PEO coatings were prepared using four different current densities with values of $0.025 \mathrm{~A} / \mathrm{cm}^{2}, 0.05 \mathrm{~A} / \mathrm{cm}^{2}, 0.1 \mathrm{~A} / \mathrm{cm}^{2}$ and 0.15 $\mathrm{A} / \mathrm{cm}^{2}$ in electrolyte consisting of $10 \mathrm{~g} / \mathrm{l} \mathrm{Na} \mathrm{PO}_{4}, 12 \mathrm{H} 2 \mathrm{O}$ and $1 \mathrm{~g} / \mathrm{l} \mathrm{KOH}$. Morphology and chemical composition of the coatings was examined using the scanning electron microscopy and EDS analysis respectively. Electrochemical characteristics of ground and coated samples were measured by means of electrochemical impedance spectroscopy (EIS) in $0.1 \mathrm{M} \mathrm{NaCl}$ solution. Obtained data in form of Nyquist diagrams were analysed by equivalent circuit method. Results of experiments showed that value of applied current density had significant effect on protective performance of the PEO coatings prepared on AZ31 magnesium alloy surface.

Keywords: magnesium alloy, plasma electrolytic oxidation, corrosion resistance

\section{Introduction}

The main reason, which impedes the wider usage of magnesium alloys in technical applications is their high reactivity and the resulting low corrosion resistance in most of the practical environments. The high rate of corrosion degradation is attributed to presence of inclusions in the structure of the $\mathrm{Mg}$ alloys which form microgalvanic cells and thus promote corrosion of the $\mathrm{Mg}$ matrix or grain boundaries. Particularly harmful elements are nickel, cobalt and iron. Another cause of insufficient corrosion resistance is the presence of a naturally created surface film based on $\mathrm{MgO} / \mathrm{Mg}(\mathrm{OH})_{2}$. The chemical composition of this film depends on the environment to which the alloy is exposed. According to the E-pH diagram, this film is stable only in strongly alkaline environments. In acidic and neutral conditions it does not provide adequate protection [1-3]. Nowadays, there are several well-known methods of protecting $\mathrm{Mg}$ alloys such as cathodic protection, platting and preparation of various coatings. The last category is one of the most evolving methods. The surface of the magnesium alloys can be modified in various ways depending on the desired final properties, with surface pre-treatment being very important as well. Frequently used surface treatment methods are cathodic electrodeposition techniques or anodic oxidation. A perspective technique called plasma electrolytic oxidation is getting a lot of scientific attention as it is a method for preparation of protective coatings on $\mathrm{Mg}$ alloy in a non-expensive way. In this process, unlike conventional anodic oxidation, much higher voltages are reached/applied and the obtained coatings have a ceramic-like character. The disadvantage is the porosity of these layers resulting from nature of the PEO process. The advantage of the PEO is that there is a variety of environmentally acceptable electrolytes and secondly it is also possible to use both DC and $\mathrm{AC}$ power sources. The preparation of such layers is relatively complicated in terms of the obtained coating properties as there is a number of variables in the PEO process such as the value of applied current/voltage, time of preparation, optimal composition of the electrolyte and the applied frequency in the case of alternating power sources. Those parameters have significant impact on the overall properties of the PEO layers [4-6]. This paper is focused on the effect of applied current density on the morphology and chemical composition of prepared layers and on corrosion protective function in an aggressive chloride containing environment.

\section{Experimental material and methods}

The experimental material AZ31 magnesium alloy produced by continuous casting has been homogenizing at $420^{\circ} \mathrm{C}$ for 16 hours. Its chemical composition, detected by the EDXRF analysis on the ARL QUANT'X EDXRF Spectrometer is shown in Table 1

Metallographic samples have been prepared according to the standard metallographic procedures recommended for magnesium alloys. The AZ31 Mg alloy microstructure has been observed by optical microscope ZEISS Axio Observer Z1.m. The images have been created using AxioVision Rel 4.5 software. An etchant consisting of $2.5 \mathrm{ml}$ of acetic acid, $2.1 \mathrm{~g}$ of picric acid, $5 \mathrm{ml}$ of demineralized water and $35 \mathrm{ml}$ of ethanol has been used to visualize the microstructure. The etching time has been set to 10 seconds. In the end samples have been rinsed by demineralized water, ethanol and dried by stream of air.

Prior to the PEO coating process, each sample has been ground by an emery paper $\mathrm{p} 1000$ to provide the same roughness across the treated surface. Subsequently, samples have been rinsed by demineralized water, ethanol and air-dried. The plasma

\footnotetext{
* 1,2Daniel Kajanek, ${ }^{2}$ Branislav Hadzima, ${ }^{3}$ Matej Brezina, ${ }^{2}$ Martina Jackova

${ }^{1}$ Department of Materials Engineering, Faculty of Mechanical Engineering, University of Zilina, Slovakia

${ }^{2}$ Research Centre, University of Zilina, Slovakia

${ }^{3}$ Faculty of Chemistry, Brno University of Technology, Czech Republic

E-mail: daniel.kajanek@fstroj.uniza.sk
} 
Table 1 Chemical composition of AZ31 magnesium alloy

\begin{tabular}{ccccccccc}
\hline Component & $\mathrm{Al}$ & $\mathrm{Zn}$ & $\mathrm{Mn}$ & $\mathrm{Si}$ & $\mathrm{Cu}$ & $\mathrm{Fe}$ & \\
\hline wt. \% & 3.31 & 0.65 & 0.23 & 0.114 & 0.004 & 0.001 & balance \\
\hline
\end{tabular}

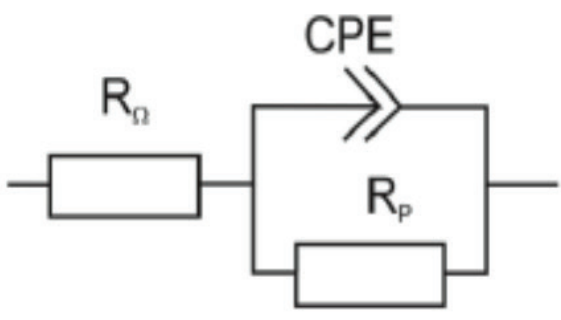

a)

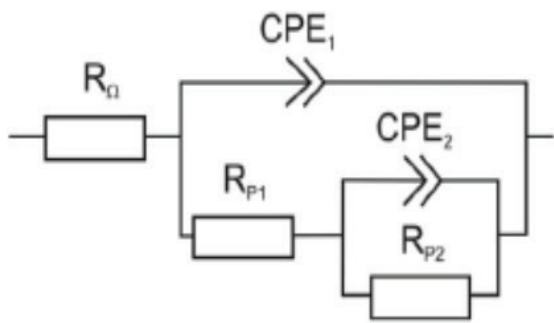

b)

Figure 1 Equivalent circuits for diagrams with one capacitance loop (a) and two capacitance loops (b)

electrolytic oxidation has been carried out using a laboratory DC power source Keysight N8762A with parameters $600 \mathrm{~V} /$ 8.5 A and output of $5100 \mathrm{~W}$. The two-electrode system has been used with the sample AZ31 involved as an anode. The cathode has been provided by stainless steel plate. The PEO has been carried out in an electrolyte composed of $10 \mathrm{~g} / 1 \mathrm{Na}_{3} \mathrm{PO}_{4} \cdot 12 \mathrm{H}_{2} \mathrm{O}$ and $1 \mathrm{~g} / 1 \mathrm{KOH}$ and its $\mathrm{pH}$ has been stabilized at 12.3. During the PEO procedure, the electrolyte has been cooled with water and constantly stirred with a laboratory stirrer for better distribution of species. The electrolyte temperature was kept below $50^{\circ} \mathrm{C}$. Four current densities with values of $0.025 \mathrm{~A} / \mathrm{cm}^{2}, 0.05 \mathrm{~A} / \mathrm{cm}^{2}$, $0.1 \mathrm{~A} / \mathrm{cm}^{2}$ and $0.15 \mathrm{~A} / \mathrm{cm}^{2}$ have been applied on the surface with the preparation time of 10 minutes. Applied current has been maintained at a constant value. The morphology of the prepared PEO coatings has been observed using the Carl Zeiss Merlin scanning electron microscope and chemical composition has been examined by EDS analysis.

Electrochemical impedance spectroscopy has been used as a tool for evaluation of the corrosion resistance of the ground and PEO coated samples. Measurements have been performed in $0.1 \mathrm{M} \mathrm{NaCl}$ at the temperature of $22 \pm 1^{\circ} \mathrm{C}$ on a laboratory potentiostat VSP Biologic. The measured frequencies have been ranged from $100 \mathrm{kHz}$ to $10 \mathrm{mHz}$. The amplitude of the applied voltage has been set to $15 \mathrm{mV}$. The mean value of the sine voltage has been equal to the open circuit potential reached after 24 hours of exposure. The outputs of these measurements are the Nyquist diagrams, which can be quantitatively described using the equivalent circuit method (Figure 1). Simple Randels circuit (Figure 1a) has been used for analysis of diagrams with one capacitance loop. Diagrams with two capacitance loops has been analysed by circuit shown in Figure 1b. The most important circuit element for evaluation of corrosion resistance is $R_{p}$ called the polarization resistance. The higher the $\mathrm{R}_{\mathrm{p}}$ value is obtained the higher corrosion resistance is provided. If the Nyquist diagram is formed by the two capacitance loops, the resulting resistance of the surface is given by the sum of the partial resistors $R_{p 1}$ and $R_{p 2}$. The element $R_{\Omega}$ expresses the resistance of the electrolyte and the element CPE (constant phase element), which replaces the capacitance $\mathrm{C}$ in the circuit, simulates the inhomogeneity of the measured surface [7].

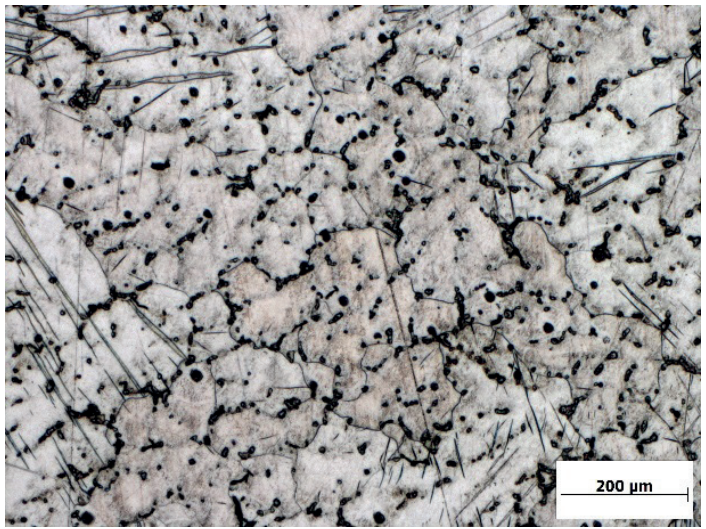

Figure 2 Microstructure of AZ31 Mg alloy

\section{Results and discussion}

The AZ31 magnesium alloy microstructure (Figure 2) is formed by polyhedral grains of solid solution of aluminum, zinc and other alloying elements in magnesium. The intermetallic phase of $\mathrm{Mg}_{17} \mathrm{Al}_{12}$ is also present in the microstructure. The average grain size is $220 \mu \mathrm{m}$. It is also possible to observe twins that were probably formed by deformation during the cutting and samples preparation [8].

The SEM images in Figure 3 show the PEO coatings prepared at a current density of $0.025 \mathrm{~A} / \mathrm{cm}^{2}$ (a) $0.05 \mathrm{~A} / \mathrm{cm}^{2}$ (b), $0.1 \mathrm{~A} / \mathrm{cm}^{2}$ (c) and $0.015 \mathrm{~A} / \mathrm{cm}^{2}$ (d). From the photo documentation, it can be seen that all the layers exhibit a porous structure typical for the PEO process. The formation of micropores is associated with the presence of molten oxides and gas bubbles produced during the discharges occurred on the surface of samples [6]. It is also possible to observe several microcracks resulting from stresses in the PEO layer during rapid solidification of molten substances in a contact with cold electrolyte $[9,10]$. Chemical composition of the coatings obtained by EDS analysis is shown in Table 2. It can be seen that from this point of view there is not a significant difference within individual coatings. Therefore it can be assumed that applied current density does not have marginal impact on the chemical composition of PEO coatings. Moreover, it is clear that PEO coatings are consisting of elements present in the electrolyte $(\mathrm{P}, \mathrm{Na}, \mathrm{O})$ and elements, which came from $\mathrm{Mg}$ substrate $(\mathrm{Mg}, \mathrm{Al})$. This claim is in good agreement with work [11]. 

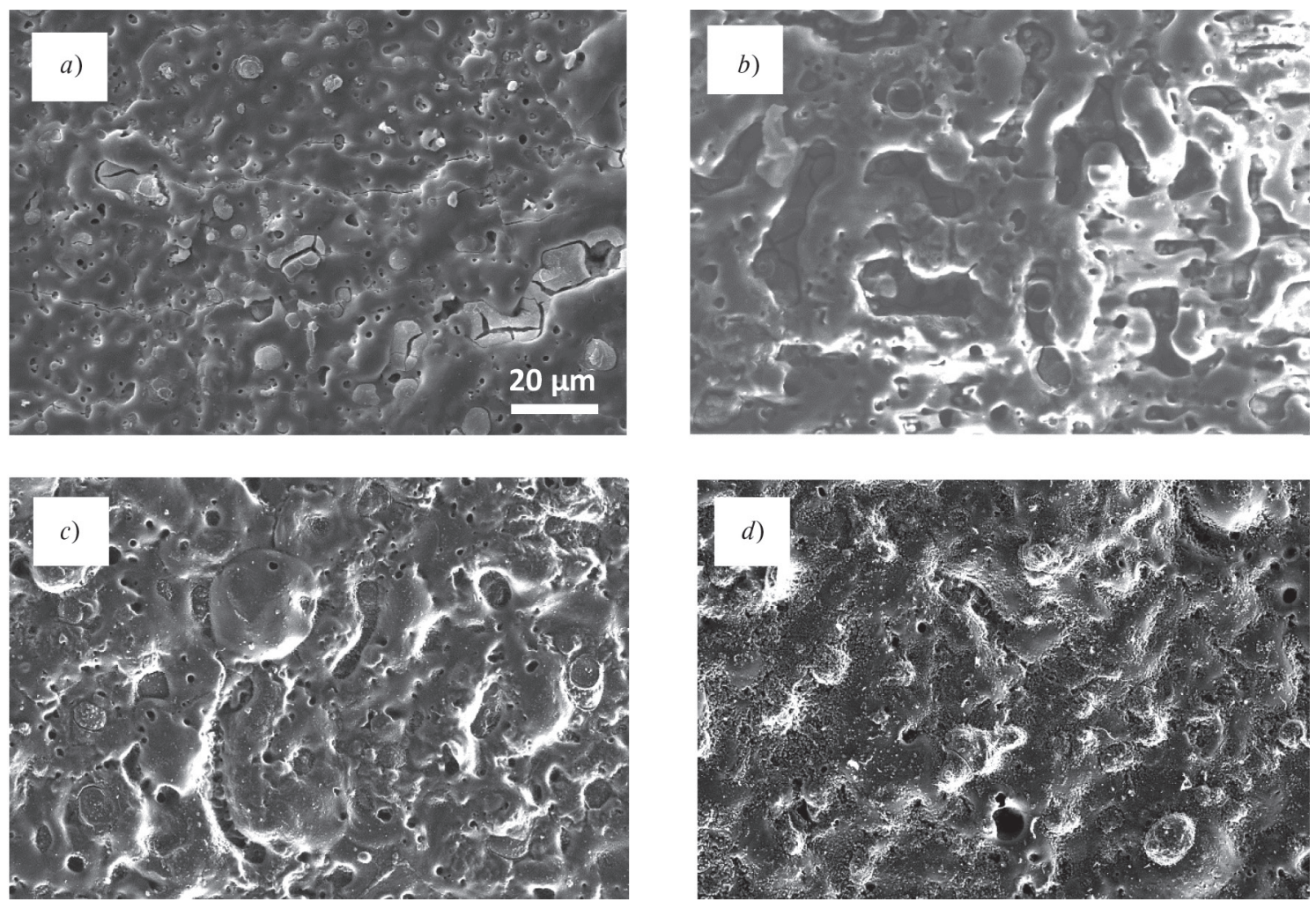

Figure 3 Morphologies of PEO coatings prepared at $0.025 \mathrm{~A} / \mathrm{cm}^{2}\left(\right.$ a) $, 0.05 \mathrm{~A} / \mathrm{cm}^{2}(b), 0.1 \mathrm{~A} / \mathrm{cm}^{2}(c)$ and $0.15 \mathrm{~A} / \mathrm{cm}^{2}$ (d), mag. $2000 x$

Table 2 Chemical composition of AZ31 magnesium alloy

\begin{tabular}{ccccc}
\hline at. \% & $0.025 \mathrm{~A} / \mathrm{cm}^{2}$ & $0.05 \mathrm{~A} / \mathrm{cm}^{2}$ & $0.1 \mathrm{~A} / \mathrm{cm}^{2}$ & $0.15 \mathrm{~A} / \mathrm{cm}^{2}$ \\
\hline $\mathrm{Mg}$ & 14.7 & 12.2 & 11.5 & 10.8 \\
$\mathrm{O}$ & 28.3 & 26.1 & 24.5 & 29.2 \\
$\mathrm{P}$ & 13.3 & 14.6 & 12.4 & 14.2 \\
$\mathrm{Al}$ & 0.34 & 0.14 & 0.15 & 0.16 \\
$\mathrm{Si}$ & - & 0.04 & 0.04 & 0.03 \\
$\mathrm{Na}$ & 1.16 & 1.74 & 1.89 & 2.68 \\
\hline
\end{tabular}

Table 3 Roughness parameters of the PEO coating prepared with different applied current density

\begin{tabular}{lcccc}
\hline & $0.025 \mathrm{~A} / \mathrm{cm}^{2}$ & $0.05 \mathrm{~A} / \mathrm{cm}^{2}$ & $0.1 \mathrm{~A} / \mathrm{cm}^{2}$ & $0.15 \mathrm{~A} / \mathrm{cm}^{2}$ \\
\hline Ra $[\mu \mathrm{m}]$ & 0.884 & 1.016 & 1.698 & 2.041 \\
Rz $[\mu \mathrm{m}]$ & 8.412 & 8.763 & 14.300 & 17.317 \\
\hline
\end{tabular}

It can be seen that with the increasing current density the layers are more rugged. This is also confirmed by roughness measurements (Table 3) which show increasing trend of Ra and $\mathrm{Rz}$ parameters with increasing energy input. Prepared coatings are formed on the surface of the magnesium alloy by intensive discharges which are responsible for formation of the layers. The higher the applied current density the more intensive/larger the discharges are occurring on the surface. However, they are less in numbers [9]. More intensive discharges consequently melt a greater amount of material and form a more rugged layer. Layers prepared at $0.1 \mathrm{~A} / \mathrm{cm}^{2}$ and $0.15 \mathrm{~A} / \mathrm{cm}^{2}$ exhibit imperfections in the form of small particles located around the pores and their occurrence is more extensive at the highest applied current density. For a more detailed description of their effect on the quality of the layer, its chemical composition will be performed and deeply studied in the future experiments.
The Nyquist diagrams for different PEO layers and ground samples measured in $0.1 \mathrm{M} \mathrm{NaCl}$ after $24 \mathrm{~h}$ of exposure are shown in Figure 4. In all the cases, except for $0.1 \mathrm{~A} / \mathrm{cm}^{2}$, the diagrams are created by two capacitive loops. Occurrence of one capacitance loop in diagram assumes homogeneous conditions on the measured surface during dissolution and two capacitance loops point to the presence of areas with different electrochemical behaviour [7]. Corresponding electrochemical characteristics are shown in Table 4. When comparing polarization resistances, it can be seen that all of the PEO layers exhibit a significantly higher $\mathrm{R}_{\mathrm{p}}$ compared to the ground sample with the value of $6765 \Omega . \mathrm{cm}^{2}$ and thus have a positive influence on the corrosion resistance. It is resulting from the formation of an effective barrier, which slows down penetration of solution and thus provides sufficient protection for the $\mathrm{Mg}$ substrate against harmful activity of the chloride ions present in testing environment. When comparing 


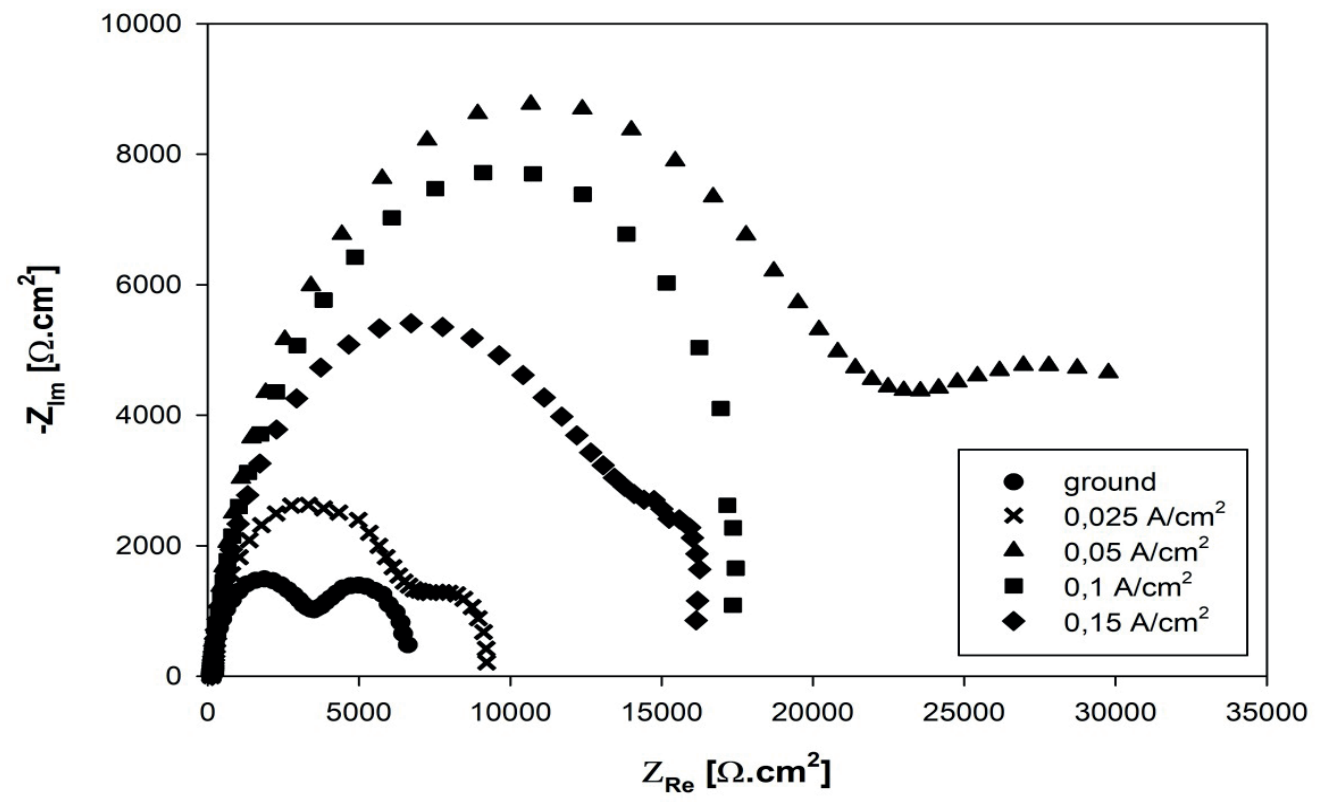

Figure 4 Nyquist plots of ground PEO treated samples of AZ31 Mg alloy measured in $0.1 \mathrm{M} \mathrm{NaCl}$

Table 4 Electrochemical characteristics of ground and PEO coated samples of AZ31 Mg alloy in $0.1 \mathrm{M} \mathrm{NaCl}$

\begin{tabular}{|c|c|c|c|c|c|c|c|c|}
\hline & $\mathrm{R}_{\Omega}\left(\Omega \cdot \mathrm{cm}^{2}\right)$ & $\begin{array}{c}\mathrm{R}_{\mathrm{pl}} \\
\left(\Omega \cdot \mathrm{cm}^{2}\right)\end{array}$ & $\begin{array}{c}\mathrm{R}_{\mathrm{p} 2} \\
\left(\Omega \cdot \mathrm{cm}^{2}\right)\end{array}$ & $\begin{array}{c}\mathrm{R}_{\mathrm{p}} \\
\left(\Omega \cdot \mathrm{cm}^{2}\right)\end{array}$ & $\begin{array}{l}\mathrm{CPE}_{1} \\
{\left[\mathrm{~F}^{\mathrm{n}} \mathrm{s}^{\mathrm{-1}}\right]}\end{array}$ & $\begin{array}{l}\mathrm{CPE}_{1} \\
{\left[\mathrm{~F} \cdot \mathrm{s}^{\mathrm{n}-1}\right]}\end{array}$ & $\mathrm{n}_{1}$ & $\mathrm{n}_{2}$ \\
\hline ground & 115 & 3699 & 3066 & 6765 & $1.10^{-5}$ & $2.10^{-3}$ & 0.9 & 0.9 \\
\hline $0.025 \mathrm{~A} / \mathrm{cm}^{2}$ & 120 & 5875 & 3340 & 9215 & $7.10^{-6}$ & $4.10^{-4}$ & 0.9 & 0.9 \\
\hline $0.05 \mathrm{~A} / \mathrm{cm}^{2}$ & 119 & 18909 & 15592 & 34501 & $6.10^{-6}$ & $2.10^{-4}$ & 0.9 & 0.7 \\
\hline $0.1 \mathrm{~A} / \mathrm{cm}^{2}$ & 128 & 18399 & - & 18399 & $6.10^{-6}$ & & 0.9 & \\
\hline $0.15 \mathrm{~A} / \mathrm{cm}^{2}$ & 133 & 11313 & 5874 & 17187 & $7.10^{-6}$ & $2.10^{-4}$ & 0.9 & 0.8 \\
\hline
\end{tabular}

the individual layers, differences in the polarization resistance values have been observed. It is obvious that polarization resistance has increased with the increasing applied current density from the $9215 \Omega . \mathrm{cm}^{2}$ reached by $0.025 \mathrm{~A} / \mathrm{cm}$ up to the applied current density of $0.05 \mathrm{~A} / \mathrm{cm}^{2}$, where the maximum of $\mathrm{R}_{\mathrm{p}}$ with the value of $34501 \Omega . \mathrm{cm}^{2}$ has been reached. With a layer prepared at $0.1 \mathrm{~A} / \mathrm{cm}^{2}$ decrease of the resistance has been observed from $18399 \Omega . \mathrm{cm}^{2}$ to the $17187 \Omega . \mathrm{cm}^{2}$ reached by the $0.15 \mathrm{~A} / \mathrm{cm}^{2}$. This trend can be explained by the synergic effects of several factors. As it was mentioned before, the roughness of the layers has increased with increasing applied current density and the occurrence of heterogeneities and larger pores associated with intensive discharges has been observed. Heterogenities and porosity has increased surface roughness and therefore larger electrochemically active area has been in contact with electrolyte $[3,4,12]$. That is why the PEO layers formed at higher current densities $\left(0.1 \mathrm{~A} / \mathrm{cm}^{2}\right.$ and $\left.0.15 \mathrm{~A} / \mathrm{cm}^{2}\right)$ have been attacked more intensively by aggressive chloride ions compared to a more uniform layer obtained at a current density of $0.05 \mathrm{~A} / \mathrm{cm}^{2}$. In the case of the layer prepared at $0.025 \mathrm{~A} / \mathrm{cm}^{2}$ its thickness and compactness are probably not high enough due to the insufficient energy input which has resulted in less intensive sparking effect and thus less promoted formation of the coating. Therefore, the lowest polarization resistance across the prepared layers has been reached. These observations are in good agreement with the results presented in works of $[11,13]$.

\section{Conclusions}

According to the performed experiments and analysis several conclusions can be stated:

- Prepared PEO coatings revealed porous structure typical for plasma electrolytic oxidation process.

- Roughness of the PEO coatings increased with the increasing applied current density. In the cases of $0.1 \mathrm{~A} / \mathrm{cm}^{2}$ and $0.15 \mathrm{~A}$ / $\mathrm{cm}^{2}$ heterogeneities were observed.

- All of the created PEO layers reached higher values of the polarization resistance compared to the ground samples in $0.1 \mathrm{M} \mathrm{NaCl}$ and thus positively influenced the corrosion resistance of $\mathrm{AZ} 31 \mathrm{Mg}$ alloy.

- The highest corrosion resistance was provided by the PEO coating created with current density of $0.05 \mathrm{~A} / \mathrm{cm}^{2}$, which reached more than 5-times higher polarisation resistance value of $34501 \Omega . \mathrm{cm}^{2}$ compared to the ground samples, which reached $R_{p}$ value of $9215 \Omega . \mathrm{cm}^{2}$.

\section{Acknowledgement}

The research was supported by the Scientific Grant Agency of the Ministry of Education, Science, Research and Sport of the Slovak Republic under the contract VEGA no. 1/0045/17 and by project ITMS 26220220121. 


\section{References}

[1] DRABIKOVA, J., et al. Improvement of bio-compatible AZ61 magnesium alloy corrosion resistance by fluoride conversion coating. Koroze a ochrana materialu [online]. 2016, 60(50), p. 132-138. ISSN 1804-1213. Avalible from: https://doi.org/10.1515/ kom-2016-0021

[2] UHRICIK, M., et al. Change of internal friction on magnesium alloy with 5.48\% $\mathrm{Al}$ and $0.813 \%$ Zn. Proceedia Engineering [online]. 2017, 177, p. 568-575. eISSN 1877-7058. Avalible from: https://doi.org/10.1016/j.proeng.2017.02.262

[3] SONG, G. L. Corrosion of Magnesium Alloys. 1. ed., Woodhead Publishing: Philadelphia, 2011. ISBN 9781845697082.

[4] MHAEDE, M., PASTOREK, F., HADZIMA, B. Influence of shot peening on corrosion properties of biocompatible magnesium alloy AZ31 coated by dicalcium phosphate dihydrate (DCPD). Materials Science and Engineering C [online]. 2014, 39, p. 330-335. ISSN 0928-4931/eISSN 1873-0191 . Avalible from: https://doi.org/10.1016/j.msec.2014.03.023

[5] DOROZHKIN, S. Calcium orthophosphate coatings on magnesium and its biodegradable alloys. Acta Biomaterialia [online]. 2014, 10(7), p. 2919-2934. ISSN 1742-7061/eISSN 1878-7568. Avalible from: https://doi.org/10.1016/j.actbio.2014.02.026

[6] YEROKHIN, A. L., et al. Plasma electrolysis for surface engineering. Surface and Coatings Technology [online]. 1991, 122(2-3), p. 73-93. ISSN 0257-8972/eISSN 1879-3347. Avalible from: https://doi.org/10.1016/S0257-8972(99)00441-7

[7] AMIRUDIN, A., THIERRY, D. Application of electrochemical impedance spectroscopy to study the degradation of polymercoated metals. Progress in Organic Coatings [online]. 2016, 26(1), p. 1-28. ISSN 0300-9440. Avalible from: https://doi. org/10.1016/0300-9440(95)00581-1

[8] KAJANEK, D.,PASTOREK, F., HADZIMA, B. Corrosion resistance of AZ31 magnesium alloy influenced by conventional cutting fluid. Materials Engineering - Materialove Inzinierstvo [online]. 2017, 24(3), p. 67-71. ISSN 1335-0803/eISSN $1338-6174$. Avalible from: http://fstroj.uniza.sk/journal-mi/PDF/2017/08-2017.pdf

[9] DARBAND, G. B., et al. Plasma electrolytic oxidation of magnesium and its alloys: Mechanism, properties and applications. Journal of Magnesium and Alloys [online]. 2017, 5(1), p. 74-132. ISSN 2213-9567. Avalible from: https://doi.org/10.1016/j. jma.2017.02.004

[10] WANG, H. M., CHEN, Z. H., LI, L. L. Corrosion resistance and microstructure characteristics of plasma electrolytic oxidation coatings formed on AZ31 magnesium alloy. Surface Engineering [online]. 2010, 26(5), p. 385-3920. ISSN 0267-0844/eISSN 17432944. Avalible from: https://doi.org/10.1179/026708410X12506873242822

[11] MORI, Y., et al. Characteristics and corrosion resistance of plasma electrolytic oxidation coatings on AZ31B Mg alloy formed in phosphate - Silicate mixture electrolytes. Corrosion Science [online]. 2014, 88, p. 254-262. ISSN 0010-938X/eISSN 1879-0496. Avalible from: https://doi.org/10.1016/j.corsci.2014.07.038

[12] KAJANEK, D., et al. Corrosion performance of AZ31 magnesium alloy treated by ultrasonic impact peening (UIP). Materials Today: Proceedings [online]. 2018, 5(13), p. 26687-26692. eISSN 2214-7853. Avalible from: https://doi.org/10.1016/j.matpr.2018.08.136

[13] DURDU, S., USTA, M. Characterization and mechanical properties of coatings on magnesium by micro arc oxidation. Applied Surface Science [online]. 2012, 261, p. 774-782. ISSN 0169-4332. Avalible from: https://doi.org/10.1016/j.apsusc.2012.08.099 